\title{
Accounting
}

\section{The effect of internal control on the performance of pharmaceutical firms in Vietnam}

\author{
Thieu Manh Nguyen ${ }^{a^{*}}$
}

${ }^{a}$ Academy of Finance, Vietnam

\section{H R O N I C L E}

\section{Article history:}

Received: September 25, 2020

Received in revised format:

September 302020

Accepted: November 7, 2020

Available online:

November 8, 2020

\section{Keywords:}

Internal control

Operational efficiency

Pharmaceutical firms

\begin{abstract}
A B S T R A C T
This article analyzes the impact of internal control on the performance of pharmaceutical companies, providing additional empirical evidence on the effects of internal control on performance. The research method used includes surveys through questionnaires distributed among pharmaceutical companies to assess internal control and each element of internal control of these firms. Quantitative research was carried out with SPSS 25 software. The results show that monitoring, information and communication are the factors that have the strongest impacts on the performance of pharmaceutical companies. This can be explained that, for pharmaceutical companies, good monitoring and information and good tradition will positively affect the effectiveness of internal control in particular and the performance of the business. Based on the research results, the author proposes some recommendations to improve the effectiveness of internal control, thereby contributing to improve the performance of pharmaceutical enterprises.
\end{abstract}

\section{Introduction}

During the operation, there is always a potential risk of weaknesses or mistakes by managers, employees or the second party and such damages may reduce the performance of the businesses. Building internal control systems is one of the very important measures since they help prevent and detect mistakes and weaknesses in order to minimize losses and improve efficiency to help the organization achieve its goals. According to the KPMG Report, currently, the pharmaceutical market in Vietnam is on a strong growth momentum with total value increasing from 2.7 billion USD in 2015 to 3.6 billion USD in 2018 at the rate of CAGR of $10.6 \%$ based on growth in the period 2015-2017. Since then, the report shows a strong development of the pharmaceutical industry, with 44,000 employees working all over the world. Based on Vietnam's recent successes in combating the COVID-19 epidemic and the ratified EVFTA, Vietnam now has an unprecedented opportunity to build an enabling environment. Attractive incentive policies, becoming the chosen destination in ASEAN for investment and long-term commitments from multinational companies in the pharmaceutical industry, especially invented pharmaceutical companies. Therefore, perfecting the internal control system to improve the operational efficiency of pharmaceutical enterprises is becoming more and more urgent. The paper systemizes empirical studies on the effect of internal control on operational efficiency, quantitative studies on the effects of internal control in general and each element of internal control in particular on the performance of pharmaceutical companies in Vietnam. The correlation regression method is used to quantify the impact of internal control on the performance of pharmaceutical companies in Vietnam. The research results are the basis for proposing solutions to improve the operational efficiency for pharmaceutical enterprises in Vietnam.

* Corresponding author. Tel.: +84904135354

E-mail address: manhthieu@hvtc.edu.vn (T. M. Nguyen) 


\section{Literature Review}

\subsection{The following theories}

There are some theories used to explain the effects of internal control factors on business performance. Chaos theory is fully applied in research. From this point of view, factors in the internal control model always interact with each other, a mistake at one stage can cause serious consequences. Agency theory was initiated by Jensen and Meckling (1976). This theory focuses on the relationship between the principal and the agent. Through delegation to minimize the manager's self-interested behavior, monitoring the attorney's behavior, and establishing and maintaining a mechanism to ensure the attorney represents the principal's interests' responsibility (in the particular case of a Vietnamese State enterprise). Contingency Theory was initiated by Wiio and Goldhaber (1993) and explains that internal control cannot be identical, the control of each organization depends on factors such as technology, culture and environment. The Theory of the Firm was initiated by Jensen and Meckling (1976), which asserts that a company in operation is to satisfy stakeholder conditions for input maximize profits (current cash flows) based on the available resources of the business. To do so, they must build internal control systems to meet this requirement. The Stakeholder theory was first initiated by Haberberg and Rieple (2001), which helps businesses identify the right parties with relevant interests and obligations (Sierpinski triangle), helps businesses define the limits, the scope of the control capacity of the business, in order to minimize risks, reduce bad impacts on the organization and ensure effective internal control.

\subsection{Literature Review}

The effects of internal control on performance have been demonstrated through many studies. Fadzil et al. (2005) suggested that effective internal control positively affects business performance. In particular, the effectiveness of internal control must be considered in terms of financial reliability, the entity having an asset protection policy, the employee must comply with policies, procedures and practices regulations of current law. Brown et al. (2008), argue that there is a positive relationship between internal control over firm income (profit after tax). Mawanda (2008) studies the impact of internal control systems on financial performance in Uganda. In this study, he examines the relationship between the internal control system and the financial performance through studying the records of the internal audit department. The research results show that there is a positive relationship between the effectiveness of the internal control system and operational efficiency, internal control is considered based on factors such as control environment, audit, internal and operational controls, and performance is measured by financial indicators such as liquidity ratios, and financial performance risk hedges. Kakucha (2009) evaluated the effectiveness of internal control and the effect of internal control on financial performance, using a sample of small firms. Research results show that internal control has a positive effect on performance and inversely related to the establishment time. Dechow et al. (2011) have studied the characteristics of enterprises where their financial statements are not dishonest and the performance of enterprises is low. He came to the conclusion that weak internal controls affect operational efficiency, at the same time lead to earnings management and, of course, a decline in stock prices. Nyakundi et al. (2014) studied the impact of internal control on the performance of SMEs in Kenya. The author uses a mixed research method to measure interpersonal relationships, elements of the internal control system and Return On Investment (ROI). Collected data are primary data through questionnaires, interviews, and secondary data are the sampled firms' financial statements. The data is analyzed by descriptive statistics, the results show that there is a significant relationship between the internal control system and the financial performance of the business. Wambugu (2014) studied the effects of internal control on the performance of non-governmental organizations (NGOs) in Kenya. Research results show that there is a positive relationship between the effectiveness of internal control and the efficiency of activities.

\section{Research methodology and research model}

\subsection{Research methodology}

The research method used includes questionnaires survey of pharmaceutical companies to assess internal control and each element of internal control of these firms. Internal control and the 5 constituent elements, measured on a five-level Likert scale of very good, good, average, not good and poor. The 5-level Likert scale is used familiarly in many studies, so the author quantifies each factor of internal control according to five levels. Quantitative research was performed with SPSS 25 software. Research scope was all pharmaceutical enterprises. Research data is collected in the form of direct interviews and email interviews of managers and employees working in many different positions in the pharmaceutical industry. Survey results collected 270 questionnaires from 300 questionnaires distributed. After excluding invalid questionnaires due to many blank boxes, the author decided to use 260 questionnaires.

\subsection{Research model}

The author uses 5 factors constituting the internal control system of COSO to build the scale, with adjustment and supplementation to suit the actual conditions of Vietnam. Dependent variable: Operational performance of pharmaceutical companies. 
Independent variable: Elements constituting the internal control system: control environment, risk assessment, control activities, information and communication, monitoring. Research model: $H Q=\alpha_{0}+\alpha_{1} X_{1}+\alpha_{2} X_{2}+\ldots+\alpha_{7} X_{5}+e_{i}$

Here: HQ: Performance of pharmaceutical companies listed on the stock market; $\mathrm{X}=\left\{\mathrm{X}_{1}, \ldots, \mathrm{X}_{5}\right\}$ : Scale variables affecting HQ; $\alpha=\{\alpha 0, \ldots, \alpha 5\}$ : Regression coefficient affects HQ; $\mathrm{e}_{\mathrm{i}}$ : error. Based on this, the research hypotheses are given as follows:

$\mathrm{H}_{1}$ : The control environment is positively correlated with the performance of pharmaceutical enterprises.

$\mathrm{H}_{2}$ : Risk assessment has a positive correlation with the performance of pharmaceutical enterprises.

$\mathrm{H}_{3}$ : Control activities are positively correlated with the performance of pharmaceutical companies.

$\mathrm{H}_{4}$ : Information and communication are positively correlated with the performance of Pharmaceutical enterprises.

H5: Monitoring has a positive correlation with the performance of pharmaceutical enterprises.

\section{Research results}

\subsection{Scale test}

The results of evaluating the reliability of the scale by Cronbach's Alpha show that all scales had reliability greater than 0.6 and total variable correlation coefficient greater than 0.3 . All scales satisfy the conditions to analyze discovery factors EFA. The reliability of the scales is summed up in Table 1.

Table 1

Test results of the scale

\begin{tabular}{clccc}
\hline No. & Variable name & Symbol & $\begin{array}{c}\text { Number of observed } \\
\text { variables }\end{array}$ & $\begin{array}{c}\text { Cronbach's Alpha } \\
\text { Coefficient total variable correlation } \\
\text { coefficient }\end{array}$ \\
\hline 1 & Environment of internal control & MT & 5 & 0.306 \\
2 & Risk assessment & RR & 4 & $0.647(\mathrm{~min})$ \\
3 & Activity control & HD & 3 & 0.740 \\
4 & Supervisor & GS & 3 & 0.825 \\
5 & Information and communication & TT & 3 & 0.784 \\
6 & operational efficiency & HQ & 4 & 0.708 \\
\hline
\end{tabular}

\subsection{Explore factor analysis EFA}

Factor analysis was performed with Principle Component extraction, Varimax rotation for the dependent observed variable. The results show that the coefficient $\mathrm{KMO}=0.834$ (meet the condition $>0.5$ ); Significance level and Bartlett test $=0.000$ (meet condition $<0.05$ ) show that EFA analysis is suitable. The total extracted variance is $55.667 \%>50 \%$; and factor load factors are greater than 0.5, so it is satisfactory. The official scale after handling EFA includes 18 observed variables as proposed.

Table 2

Results of factor analysis to discover EFA independent variables

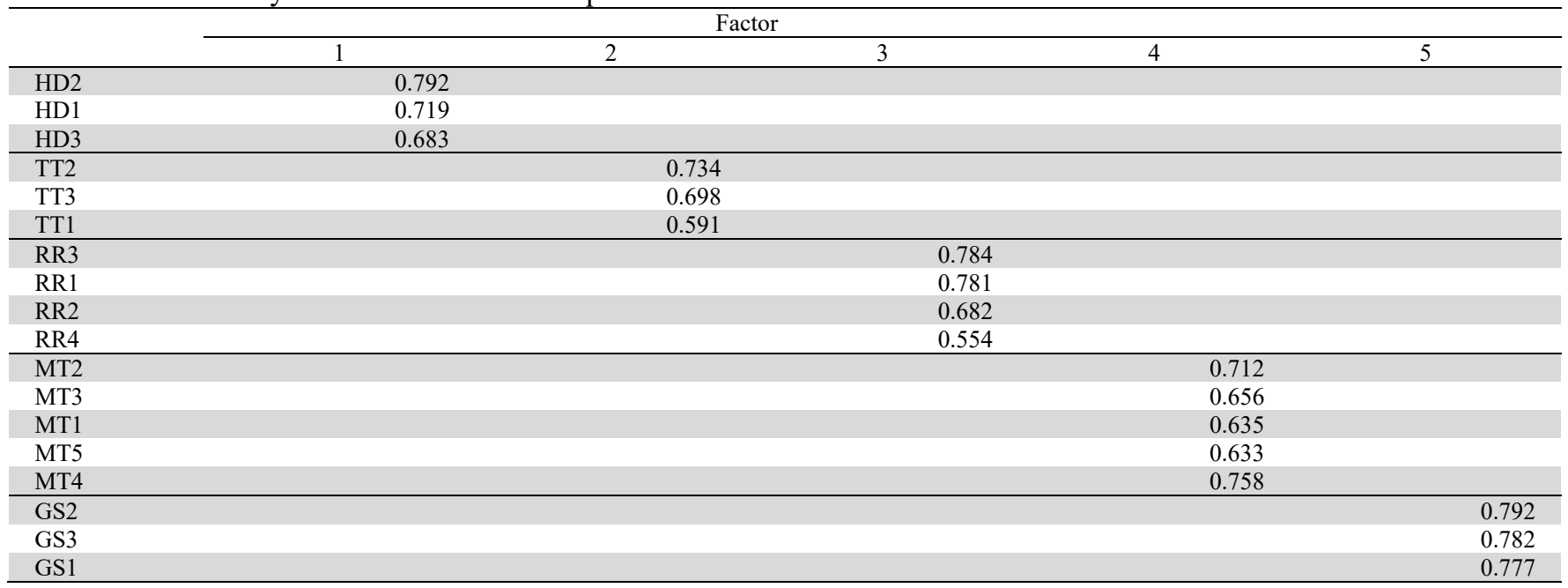




\subsection{Regression analysis}

Table 3

Results Statistical value factors

\begin{tabular}{lcccc}
\hline & \multicolumn{4}{c}{ model Abstract } \\
\cline { 2 - 4 } Model & $\mathrm{R}$ & R squared & adjusted R-squared & error estimate of standard deviation, \\
\hline 1 & 0.828 & 0.673 & 0.665 & 0.54186 \\
\hline a. Predictors: (Constant), Information and communications, Internal control environment, Risk assessment, Monitoring, Control activities \\
b. Dependent Variable: Corrected operating
\end{tabular}

R-squared efficiency reflects the influence of the independent variables on the variation of the dependent variable, in this case 5 factors (Information and communication, Control environment internal, risk assessment, monitoring, control), affecting $66.5 \%$ of the performance of enterprises in the pharmaceutical industry. Factors other than the model and random error affect $33.6 \%$ on the performance factor of pharmaceutical companies. The Durbin-Watson coefficient is 1,542, which is in the range from 1.5 to 2.5 , so there is no first order sequence autocorrelation. In order to check whether this regression model is suitable for the collected data set and has application significance, the author continues to test the model's suitability through ANOVA test as follows:

\section{Table 4}

Suitability test (ANOVA)

\begin{tabular}{|c|c|c|c|c|c|c|}
\hline Model & & Sum of Squares & df & Mean Square & $\mathrm{F}$ & Sig. \\
\hline \multirow[t]{3}{*}{1} & Regression & 126.748 & 4 & 25.350 & 84.597 & 0.000 \\
\hline & Residual & 74.577 & 254 & 0.2945 & & \\
\hline & Total & 21.325 & 259 & & & \\
\hline
\end{tabular}

a. Dependent Variable: Efficiency

b. Predictors: (Constant), Information and communication, Internal control environment, Risk assessment, Monitoring, Control operation

Sig tested $\mathrm{F}=0.000<0.05$, so the regression model assesses the impact level of 5 factors (Information and communication, Internal control environment, Risk assessment, Monitoring, Control activities) to the performance of pharmaceutical companies. The model's F-statistic has the value Sig. $=0.000<0.05$ indicates that the model is suitable for the data set and can be deduced overall. VIF coefficients are all less than 2 , so there is no multicollinearity phenomenon between the components that does not appear in the research model. The regression results show the influence of 5 elements of internal control on performance is shown in the table below:

Table 5

Results of a multiple regression

\begin{tabular}{|c|c|c|c|c|c|c|c|c|}
\hline \multicolumn{9}{|c|}{ coefficient } \\
\hline & \multirow[b]{2}{*}{ model } & no & ardized coefficient & \multirow{2}{*}{$\begin{array}{c}\begin{array}{c}\text { standardized } \\
\text { coefficient }\end{array} \\
\text { Beta }\end{array}$} & \multirow[b]{2}{*}{$\mathrm{t}$} & \multirow[b]{2}{*}{ Sig. } & \multicolumn{2}{|c|}{ Multi-statistics } \\
\hline & & $\mathrm{B}$ & Collinear Std. Error & & & & Tolerance & VIF \\
\hline \multirow[t]{6}{*}{1} & (Constant) & 0.059 & 0.277 & & 1.040 & 0.000 & & \\
\hline & Environment internal control & 0.113 & 0.073 & 0.112 & 0.176 & 0.000 & 0.782 & 1.279 \\
\hline & Risk assessments & 0.213 & 0.062 & 0.215 & 0.211 & 0.003 & 0.723 & 1.382 \\
\hline & control activities & 0.167 & 0.047 & 0.113 & 1.416 & 0.000 & 0.567 & 1.763 \\
\hline & Monitoring & 0.335 & 0.044 & 0.354 & 0.799 & 0.005 & 0.784 & 1.276 \\
\hline & Information and communication & 0.215 & 0.050 & 0.277 & 2.320 & 0.001 & 0.618 & 1.619 \\
\hline
\end{tabular}

a. Dependent Variable: Operational efficiency

The regression model is written as follows:

$Y=0.059+0.11112 X_{1}+0.215 X_{2}+0.113 X_{3}+0.354 X_{4}+0.277 X_{5}+E$

where: $Y$ is the operational efficiency Dynamic

$X_{1}$ : Internal control environment; $X_{2}$ : Risk assessment; $X_{3}$ : Operational control; $X_{4}$ : Supervision; $X_{5}$ : Information and communication; $E$ : Residual

Fig. 1 also shows the histogram of normalized residual frequency chart with very small average value close to $0($ Mean $=5.7 \mathrm{E}$ - 16) and standard deviation close to 1 (0.990). Thus, the normal distribution of the remainder is not violated. 


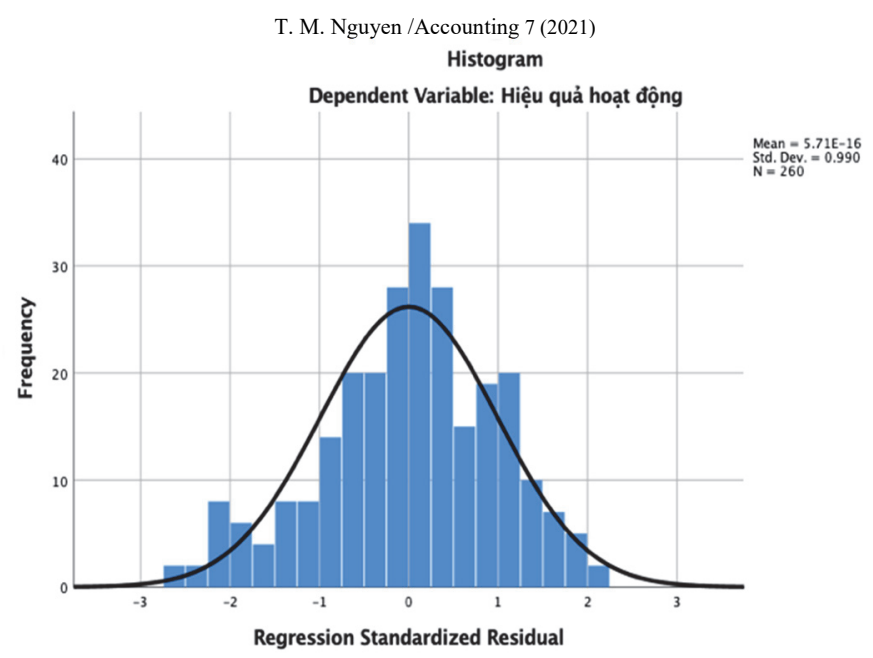

\section{Discussion and recommendations}

Fig. 1. The results of residual

\subsection{Discussion}

On the basis of the results of quantitative research on internal control factors to the performance of pharmaceutical enterprises, the following conclusions can be drawn:

The multiple linear regression equation extracted according to the Normalized Beta coefficient shows that the monitoring factor has a higher standardized Beta coefficient (0.354) than all other factors. Standardized Beta coefficients of the remaining factor are: Internal control environment (0.1112), Risk assessment (0.215), Control activity (0.113), Information and communication (0.277), Phuc benefits (0.004), training and promotion opportunities $(0.013)$

Thus, monitoring, information and communication are the factors that have the strongest impacts on the performance of pharmaceutical companies. This can be explained that, for pharmaceutical companies, good monitoring and information as well as good tradition will positively affect the effectiveness of internal control in particular and the performance of the business. Generally speaking.

\subsection{Recommendations}

From the research results on the effects of internal control on the performance of pharmaceutical companies, the author gives a number of recommendations to improve the internal control system, thereby contributing to the part to improve the operational efficiency of pharmaceutical enterprises as follows:

- Completing the control environment: New businesses need to focus on building human resource policies to cope with the changing business environment.

- Complete risk assessment: Pharmaceutical companies need to build a set of risk management parts of the company, regularly assess risks that businesses may encounter such as exchange rate risk, credit risk.

- Completing control activities: Pharmaceutical enterprises need to strengthen their control activities, namely, to control product quality and cost.

- Information and communication: Disclosure of information transparency is an important part of corporate governance practice, and annual financial statements must be audited for integrity.

- Strengthening supervision, especially external supervision: The improvement of the internal control system, through monitoring as a tool to promote corporate governance reform to further strengthen accountability and improve efficiency and effectiveness in management and use of public resources rather than applying a passive development perspective.

\section{References}

Brown, N. C., Pott, C., \& Wömpener, A. (2008). The effect of internal control regulation on earnings quality: Evidence from Germany. University of Southern California, Los Angeles, CA. 
COSO (2013), Internal Control - Integrated Framework Executive Summary https://www.COSO.org/Documents/990025PExecutive-Summary-final-may20.pdf (pdf)

Dechow, P. M., Ge, W., Larson, C. R., \& Sloan, R. G. (2011). Predicting material accounting misstatements. Contemporary Accounting Research, 28(1), 17-82.

Fadzil, F. H., Haron, H., \& Jantan, M. (2005). Internal auditing practices and internal control system. Managerial Auditing Journal, 20(8), 844-866.

Kakucha, W. (2009). An evaluation of internal controls: the case of Nairobi small businesses (Doctoral dissertation, Strathmore University).

Haberberg, A., \& Rieple, A. (2001). The strategic management of organisations. FT Prentice Hall.

Jensen, M. C., \& Meckling, W. H. (1976). Theory of the firm: Managerial behavior, agency costs and ownership structure. Journal of Financial Economics, 3(4), 305-360

Mawanda, S. P. (2008). Effects of internal control systems on financial performance in an institution of higher learning in Uganda. A Postgraduate Dissertation.

Nyakundi, D. O., Nyamita, M. O., \& Tinega, T. M. (2014). Effect of internal control systems on financial performance of small and medium scale business enterprises in Kisumu City, Kenya. International Journal of Social Sciences and Entrepreneurship, 1(11), 719-734.

Wambugu, L. (2014). Effects of Organizational Culture on Employee Performance (Case Study of Wartsila-Kipevu Ii Power Plant). European Journal of Business and Management, 6(32).

Wiio, I., \& Goldhaber, G. (1993). Organizational communication. Mac Graw Hill (6th Ed.), New York.

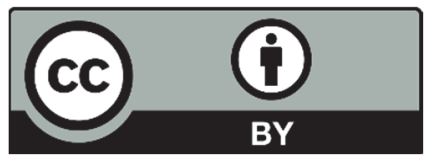

(C) 2021 by the authors; licensee Growing Science, Canada. This is an open access article distributed under the terms and conditions of the Creative Commons Attribution (CC-BY) license (http://creativecommons.org/licenses/by/4.0/). 